\title{
Efficiency of Banks in Malaysia: a Super Efficiency Approach
}

\author{
Maznah Mat Kasim ${ }^{*}$, Razamin Ramli², Md. Azizul Baten ${ }^{3}$, Jastini Mohd Jamil ${ }^{4}$, Mushtaq Taleb $^{5}$ \\ ${ }^{1,2,4}$ Universiti Utara Malaysia \\ 06010 Sintok, Kedah, Malaysia \\ E-mail."maznah@uum.edu.my(correspondingauthor),razamin@uum.edu.my,jastini@uum.edu.my
}

${ }^{3}$ Shahjalal University of Science and Technology

University av, Sylhet 3114, Bangladesh

E-mail.baten_math@yahoo.com

${ }^{5}$ University of Anbar

11, Ramadi, Iraq

E-mail.mushtaqtaleb@gmail.com

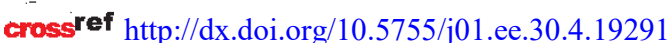

\begin{abstract}
The stability of the economic system of a country very much depends on its banking industry. Data Envelopment Analysis (DEA) has been applied widely for measuring efficiency of banks. Limited studies, however, have employed the radial and non-radial DEA models to evaluate efficiency of banks without considering the ranking of the fully efficient banks since those banks have the same efficiency score. Considering the weakness of the radial and non-radial DEA, this paper aims to calculate the banks efficiency of nine commercial banks in Malaysia from 2004 to 2013 by adopting the two-stage of super efficiency slack-based measure (SE-SBM) model. This model can discriminate between the efficient banks and recalculate their efficiency scores. Then, the selected banks were able to be ranked according to their final efficiency scores. Moreover, comparative analyses of the efficiency of the banks and the year-wise efficiency of the selected banks were also conducted. The methodology consists of two stages. In the first stage the SBM model is run to classify efficient and inefficient banks. In the second stage the super efficiency model is run to rank the efficient banks obtained from the first stage by calculating their super efficiency scores. Our empirical results show that: (1) the efficiency status of the banks fluctuated over the examined period, the high number of the efficient banks is achieved in the years 2006 and 2008, while the year 2012 has the lowest number of the efficient banks. (2) the ranking of the banks fluctuated in the studied period. (3) most of the banks are inefficient in terms of their average efficiency scores. This paper has two limitations. First, the paper did not integrate undesirable output, despite it deals with non-interest income. Second, performance evaluation of Malaysian commercial banks was only compared among the Malaysian banks.
\end{abstract}

Keywords: Data Envelopment Analysis; Malaysian Commercial Banks; Slack-Based Measure; Super Efficiency.

\section{Introduction}

The bank sector represents the main source of long-term investment and achieves the economic growth (Sufian \& Kamarudin, 2014). In developing countries such as Malaysia, the bank sector is strongly related to the financial system. The stability of its financial system really depends on its banking performance. Therefore, it represents the backbone of the economic development (Levine, 1998). Modern banking business has drastically transformed over the years due to globalization, and information technologies development (Titko, Stankeviciene \& Lace, 2014). To be able to survive in the digital era, and to achieve a high level of economic development, the performance or efficiency of bank sector needs to be measured (Ataullah \& Le, 2006). Performance of banks is related to other important issues such as competition, productivity, efficiency and profitability. The efficiency measure ensures that the banks keep profitable. In recent years, many studies have examined the efficiency of banks with parametric and non-parametric frontier approaches (Sufian \& Haron, 2009; Staub, Souza, \& Tabak, 2010;
Ouenniche \& Carrales, 2018; Baten, Kasim, \& Rahman, 2015). Most of these studies used a non-parametric approach which is called Data Envelopment Analysis (DEA) (Avkiran, 2011).

DEA is a mathematical programming approach proposed by Charnes et al. (1978) for measuring the efficiency of a peer set of homogenous decision making units (DMUs), which consume multiple inputs to produce multiple outputs. There are two types of efficiency measures in DEA, radial and nonradial. The radial model assumes proportional reduction of inputs (input-oriented) or proportional expansion of outputs (output oriented) and it ignores an existence of input and output slacks in the efficiency score. These limitations of the model lead to inaccurate efficiency measures (Chiu et al., 2011)

In order to obtain precise efficiency measure, non-radial models are more suitable since they simultaneously deal with input and output slacks at different rates (Charnes et al., 1985; Morita et al., 2005). Tone (2001) proposed a non-radial SBM model to effectively discriminate efficient and inefficient DMUs. However, Tone's (2001) model is not able to 
discriminate between the high performers DMUs (i.e., fully efficient). To discriminate between fully efficient DMUs, Tone (2002) constructed a super efficiency slack-based measure (SE-SBM) model by excluding the efficient $\mathrm{DMU}_{\mathrm{o}}$ from its efficient frontier of the SBM model. The model measures the non-radial distance between an excluded efficient DMU and the efficient frontier formed by the remaining efficient DMUs; thus, it deals with slacks of input and output simultaneously (Hussain et al., 2016). This feature of Tone's (2002) model made it more appropriate in dealing with real life applications. Despite the salient features of the SE-SBM model, it was not use yet in evaluating the efficiency of Malaysian banks. Hence, the aim of this paper is to evaluate efficiency of main commercial banks in Malaysia, for a period of ten years, that is from 2004 to 2013, and to identify the banks' ranks using the formulation of the SE-SBM model, thus improving the methodology of measuring the efficiency of Malaysian banks. The formulated SE-SBM calculates for the first time, input saving (i.e., maximum level of an input allowable to increase) and output surplus (i.e., minimum level of an output allowable to decrease) of the commercial banks in Malaysia. The applied methodology of this paper is based on Tone's (2002) model by discriminating among efficient and inefficient commercial banks. The discrimination process is obtained by identifying increasing in inputs (input saving) and decreasing in outputs (output surplus).

In order to achieve the aim of the paper, this paper is set out as follows: Section 2 provides literature review related to the efficiency studies in banks sector. Section 3 presents the methodology of this paper in evaluating banks' efficiency using the SE-SBM model. Section 4 discusses the results from different empirical tests, while concluding remarks are discussed in Section 5.

\section{Literature Review}

In literature of banks' efficiency, there have been many studies conducted under the two efficiency measures of DEA; i.e., radial and non-radial. The studies that used radial model as those introduced by Ataullah et al. (2004), Casu and Molyneux (2003), Favero and Papi (1995), Li (2006), and McAllister and McManus (1993). The radial model concentrates on proportional changes in input (input-oriented model) or (output-oriented model) and it cannot deal simultaneously with input and output slacks. Thus, the radial model is not able to reflect all efficiency of inefficient DMUs (Cooper et al., 1999). To deal simultaneously with slacks of inputs and outputs, non-radial models have been proposed. The non-radial additive model was proposed by Charnes et al. (1985) to simultaneously deal with input-output slacks. However, its objective function cannot measure in-depth efficiency for inefficient DMUs since its value depends on measurement of inputs and outputs (i.e., non-commensurate) (Cook \& Seiford, 2009). To overcome this issue, Tone (2001) proposed slack-based measure model (SBM) whose objective function is unit invariant and its value ranged from zero to one. Since then, several efficiency studies in bank sector have been conducted based on the Tone's (2001) model (e.g., Drake \& Hall, 2003; Sufian \& Kamarudin, 2014; Zhao \& Kang, 2015; Yin, Yu, \& Huang, 2018; Zha, Liang, Wu, \& Bian, 2016; Wang, Hang, Sun, \& Zhao; 2016; Wang, Huang, $\mathrm{Wu}, \&$ Liu, 2014).
All these studies are unable to discriminate between efficient DMUs. To discriminate and rank efficient banks, several studies have been conducted under the super efficiency radial model such as Deng et al. (2007), Khodabakhshi et al. (2010), Rahim (2015). Rahim (2015) analysed and compared between the technical efficiency of foreign and domestic Malaysian commerical banks over the examined period 2000 to 2010 . The results obtained indicate that the performance of the domestic banks is better than of the foreign banks. Since the super efficiency radial model which proposed by Andersen and Petersen (1993) suffered from the infeasibility issue under the technology of variable return to scale (VRS), Tone (2002) proposed a super efficiency slack-based measure (SE-SBM) model. The model has several salient features which are: (i) the model deals with input and output slacks simultaneously, (ii) it achieves the feasibility under the two technologies of constant return to scale (CRS) and variable return to scale (VRS) because it determines the maximum increasing in inputs (input saving) and maximum decreasing in outputs (output surplus), (iii) its objective function is invariant, and (iv) its scalar measure simultaneously deals with input excess/output shortfall (Du et al., 2010; Duzakın \& Duzakın, 2007; Hussain et al., 2016; Taleb et al., 2018). All these features have made the model is more appropriate in evaluating the efficiency of an organization seeking both input reduction and output augmentation. Based on SE-SBM model, limited efficiency studies in bank sector have been introduced (e.g., Chiu et al., 2011; Chiu et al., 2008; Zhao \& Kang, 2015). In addition, a new scheme of the SESBM model that deals with negative outputs was formed by Lo and Lu (2009), their model has been used to evaluate efficieny of financial companies in Taiwan. Hence, this paper explores the potential of the SE-SBM model in evaluating and analysing the efficiency of the Malaysian commerical banking sector. To the best of our knowledge, there has not been efficiency study used the SE-SBM model to evaluate efficiency of banks sector in Malaysia.

\section{Methodology}

This section discusses the methodology of the SE-SBM model in discriminating among efficient and inefficient DMUs and ranking them. To do that, we adopt the two-stage model of Tone (2002) to evaluate the efficiency of nine commercial banks in Malaysia from 2004 to 2013 as follows.

\section{Slack-Based Measure (SBM) Model}

To evaluate and analyse the bank's efficiency based on the SE-SBM model, we first run the SBM model of Tone (2001) to discriminate between efficient and inefficient banks. The non-radial SBM model evaluates the efficiency of $D M U_{j}$ under evaluation $(j=1, \ldots, n)$ where $n$ is the number of DMUs that need to evaluate; $x_{i j}>0, i=1, \ldots, m$; $y_{r j}>0, r=1, \ldots, s$ are the $i$ th input and $r$ th output, respectively for the $j$ th DMU. $\lambda_{j}$ denotes the intensity factor of the efficient $D M U_{o}$, where $o$ denotes factor reflecting the DMU under evaluation. The production possibility set (PPS) of the model is defined as 


$$
P_{S B M}=\left\{(x, y) \mid x \geq \sum_{j} x_{j} \lambda_{j}, y \leq \sum_{j} y_{j} \lambda_{j}, \lambda_{j} \geq 0\right\}
$$

The fractional form of the SBM model is described as follows:

$$
\min \varphi=\frac{1-\frac{1}{m}\left(\sum_{i=1}^{m} \frac{s_{i}^{-*}}{x_{i o}}\right)}{1+\frac{1}{s}\left(\sum_{r=1}^{s} \frac{s_{r}^{+^{*}}}{y_{r o}}\right)}
$$

s.t.

$$
\begin{array}{cc}
x_{i o}=\sum_{j=1}^{n} x_{i j} \lambda_{j}^{*}+s_{i}^{-^{*}}, & i=1, \ldots, m \\
y_{r o}=\sum_{j=1}^{n} y_{r j} \lambda_{j}^{*}-s_{r}^{+^{*}}, & r=1, \ldots, s \\
\lambda_{j}^{*} \geq 0, s_{i}^{-^{*}} \geq 0, s_{r}^{+^{*}} \geq 0, & j=1, \ldots, n
\end{array}
$$

To construct the efficient frontier under the technology of CRS, the value of $\varphi$ should be equal to one and all values of input excess $s_{i}^{-}$and output shortfall $s_{r}^{+}$are equal to zero. Thus, the efficiency score reveals the global technical efficiency and $D M U_{o}$ is SBM-efficient, otherwise the $D M U_{o}$ is SBM-inefficient. To obtain the optimal solution, the fractional model, i.e., model. (2) should be transformed into linear form using Charnes and Cooper (1962) as follows:

$$
\begin{aligned}
& \text { by assuming } 1 / t+\frac{1}{s}\left(\sum_{r=1}^{s} \frac{s_{r}^{+}}{y_{r o}}\right) \text {, } \\
& \min \tau^{*}=t-\frac{1}{m}\left(\sum_{i=1}^{m} \frac{\hat{s}_{i}^{-}}{x_{i o}}\right) \\
& \text { s.t } \\
& t+\frac{1}{s}\left(\sum_{r=1}^{s} \frac{\hat{s}_{r}^{+}}{y_{r o}}\right)=1 \\
& t x_{i o}=\sum_{i=1}^{m} x_{i j} \hat{\lambda}_{j}+\hat{s}_{i}^{-}, \quad i=1, \ldots, m \\
& t y_{r o}=\sum_{r=1}^{s} y_{r j} \hat{\lambda}_{j}-\hat{s}_{r}^{+}, \quad r=1, \ldots, s \\
& \hat{\lambda}_{j} \geq 0, \hat{s}_{i}^{-} \geq 0, \hat{s}_{r}^{+} \geq 0, \quad j=1, \ldots, n
\end{aligned}
$$

An optimal solution of model (3) is defined as $\tau^{*}, \hat{s}_{i}^{-}, \hat{s}_{r}^{+}, \hat{\lambda}$. Thus, an optimal solution of model (2) can be obtained as

$$
\varphi^{*}=\tau^{*}, \bar{s}_{i}^{*}=\hat{s}_{i}^{-} / t, s_{r}^{+^{*}}=\hat{s}_{r}^{+} / t, \lambda^{*}=\hat{\lambda} / t .
$$

\section{Super Efficiency-SBM Model}

In reality situations, it is possible that multiple DMUs achieve the fully-efficient status. To discriminate among the efficient DMUs, the super efficiency (SE) model should be employed. The SE status of an efficient $D M U_{o}$ is identified by excluding the efficient $D M U_{o}$ from its reference set. However, the main issue is how to identify the distance between the excluded efficient $D M U_{o}$ and the efficient frontier constructed by the remaining efficient DMUs. The distance reflects the possible amount of increasing inputs (input saving) and decreasing outputs (output surplus) of the excluded efficient $D M U_{o}$ The aim of the input saving and output surplus is to achieve the SE status by measuring the ability of the excluded efficient $D M U_{o}$ to move on the efficient frontier. To calculate input saving and output surplus of the excluded efficient $D M U_{o}$, the SE-SBM model of Tone (2002) is a suitable solution. Based on values of input saving and output surplus, the SE score of the observed $D M U_{o}\left(x_{i o}, y_{r o}\right)$ is identified. Thus, the model can be presented as follows:

$$
\min \phi^{S E}=\frac{\frac{1}{m} \sum_{i=1}^{m}\left(\frac{x_{i o}+z_{i o}^{-}}{x_{i o}}\right)}{\frac{1}{s} \sum_{r=1}^{s}\left(\frac{y_{r o}-z_{r o}^{+}}{y_{r o}}\right)}
$$

s.t.

$$
\begin{array}{lc}
\sum_{j=1, j \neq o}^{n} x_{i j} \lambda_{j} \leq x_{i 0}+z_{i o}^{-}, & i=1, \ldots, m \\
\sum_{j=1, j \neq o}^{n} y_{r j} \lambda_{j} \geq y_{r 0}-z_{r o}^{+}, & r=1, \ldots, s \\
\lambda_{j} \geq 0, & j=1, \ldots, n, j \neq o \\
z_{i o}^{-}, z_{r o}^{+} \geq 0, \quad \forall_{i, r} &
\end{array}
$$

The points $\left(x_{i o}+z_{i o}^{-}, y_{r o}-z_{r o}^{+}\right)$represent the maximum level of the $i$ th input and minimum level of the $r$ th output of the $D M U_{o}$. The numerator of the objective function represents the weighted distance from $x_{i o}$ to $x_{i o}+z_{i o}^{-}$ $\left(>x_{i o}\right)$; thus, it reflects an average expansion rate of $x_{i o}$ to $x_{i o}+z_{i o}^{-}$for $D M U_{o}$. The dominator reflects the weighted distance from $y_{r o}$ to $y_{r o}-z_{r o}^{+}\left(<y_{r o}\right)$. Hence, it reflects an average reduction rate of $y_{r o}$ to $y_{r o}-z_{r o}^{+}$. The objective function of model (4) can be rearranged by replacing its slacks of input saving and output surplus $z_{i o}^{-}, z_{\text {ro }}^{+}$, respectively with $x_{i o}+z_{i o}^{-}, y_{\text {ro }}-z_{\text {ro }}^{+}$, respectively. Thus, model (4) becomes as

$$
\min \phi^{S E}=\frac{1+\frac{1}{m} \sum_{i=1}^{m}\left(\frac{z_{i o}^{-*}}{x_{i o}}\right)}{1-\frac{1}{S} \sum_{r=1}^{s}\left(\frac{z_{r o}^{+*}}{y_{r o}}\right)}
$$

s.t.

$$
\sum_{j=1, j \neq o}^{n} x_{i j} \lambda_{j}^{*} \leq x_{i 0}+z_{i o}^{-^{*}}, \quad i=1, \ldots, m
$$


Maznah Mat Kasim, Razamin Ramli, Md. Azizul Baten, Jastini Mohd Jamil, Mushtaq Taleb. Efficiency of Banks in ...

$$
\begin{array}{lc}
\sum_{j=1, j \neq o}^{n} y_{r j} \lambda_{j}^{*} \geq y_{r 0}-z_{r o}^{+*}, & r=1, \ldots, s \\
\lambda_{j}^{*} \geq 0, & j=1, \ldots, n, j \neq o \\
z_{i o}^{-*}, z_{r o}^{+*} \geq 0, \quad \forall_{i, r} &
\end{array}
$$

Note that model (5) is a fractional form; thus, it should be transformed into a linear form to obtain an optimal solution as illustrated follows.

$$
\min \delta^{S E}=t+\frac{1}{m} \sum_{i=1}^{m}\left(\frac{\hat{z}_{i o}^{-}}{x_{i o}}\right)
$$

s.t.

$$
\begin{array}{ll}
t-\frac{1}{s} \sum_{r=1}^{s}\left(\frac{\hat{z}_{r o}^{+}}{y_{r o}}\right)=1 & \\
\sum_{j=1, j \neq o}^{n} x_{i j} \hat{\lambda}_{j} \leq t x_{i 0}+\hat{z}_{i o}^{-}, & i=1, \ldots, m \\
\sum_{j=1, j \neq o}^{n} y_{r j} \hat{\lambda}_{j} \geq t y_{r 0}-\hat{z}_{r o}^{+}, & \\
\hat{\lambda}_{j} \geq 0, & j=1, \ldots, s
\end{array}
$$

$$
\hat{z}_{i o}^{-}, \hat{z}_{\text {ro }}^{+} \geq 0, \quad \forall_{i, r}
$$

An optimal solution of model (6) is identified as $\delta^{S E}, \hat{z}_{i}^{-}, \hat{z}_{r}^{+}, \hat{\lambda}$. Thus, an optimal solution of model (5) can be obtained as

$$
\phi=\delta^{*}, z_{i}^{-*}=\hat{z}_{i}^{-} / t, z_{r}^{+^{*}}=\hat{z}_{r}^{+} / t, \lambda^{*}=\hat{\lambda} / t .
$$

For more detail (see Tone, 2002; Lo \& Lu, 2009).

\section{Using SE-SBM Model to Evaluate Performance of Malaysian Banks}

\section{Data Set}

This paper utilizes a sample of nine commerical banks in Malaysian from 2004 to 2013 to evaluate the efficiency of the banks using the SE-SBM model of Tone (2002). Each bank denotes as an independent DMU. In this paper, we considered three inputs and two outputs. The inputs are: deposits, fixed assets, and capital (Chen et al., 2010; Chiu

\begin{tabular}{|c|c|c|c|c|c|c|c|c|c|c|}
\hline Variables & Banks & AFIN & МYРВ & AMМВ & BIMB & COMBS & HOLB & HONG & MALY & RHBC \\
\hline \multirow[t]{2}{*}{$x_{1}$} & Mean & 17.2133 & 16.9602 & 17.7969 & 16.8662 & 18.8326 & 18.0270 & 18.0239 & 19.1495 & 18.2260 \\
\hline & S.D. & 0.2876 & 0.2591 & 0.3555 & 0.3967 & 0.4782 & 0.4517 & 0.4536 & 0.4210 & 0.3818 \\
\hline \multirow[t]{2}{*}{$x_{2}$} & Mean & 17.5487 & 17.2204 & 18.2684 & 17.1561 & 19.1718 & 18.2758 & 18.3555 & 19.5316 & 18.6115 \\
\hline & S.D. & 0.2365 & 0.2159 & 0.2549 & 0.3915 & 0.4256 & 0.4363 & 0.4410 & 0.3961 & 0.2940 \\
\hline \multirow[t]{2}{*}{$x_{3}$} & Mean & 15.4605 & 15.0437 & 16.3085 & 14.2183 & 17.2423 & 15.8691 & 16.0175 & 17.4110 & 16.4651 \\
\hline & S.D. & 0.2284 & 0.2692 & 0.2272 & 1.4421 & 0.4683 & 0.6014 & 0.5909 & 0.5584 & 0.4258 \\
\hline \multirow[t]{2}{*}{$y_{1}$} & Mean & 13.0148 & 12.7905 & 14.3373 & 12.7860 & 15.0333 & 13.4325 & 13.8742 & 15.3974 & 14.0653 \\
\hline & S.D. & 0.1836 & 0.3111 & 0.2831 & 0.5827 & 0.5566 & 0.4306 & 0.3396 & 0.5758 & 0.3565 \\
\hline \multirow[t]{2}{*}{$y_{2}$} & Mean & 15.9163 & 15.5816 & 16.3031 & 15.8863 & 17.5595 & 16.5225 & 16.8384 & 17.6641 & 17.0427 \\
\hline & S.D. & 0.1731 & 0.5443 & 0.2902 & 0.6813 & 0.4113 & 0.6147 & 0.5340 & 0.5485 & 0.3017 \\
\hline
\end{tabular}
et al., 2008; Zhao \& Kang, 2015). The two outputs are: noninterest income (Chen et al., 2010; Chiu et al., 2008), and investments (Asmild \& Matthews, 2012). The inputs and outputs of the data set is presented in Table 1 . Table 2 shows the descriptive statistics of the input/outputs.

Definitions of the Input and Output Factors

\begin{tabular}{ll}
\hline Input factor & Definition \\
\hline Deposits $\left(x_{1}\right)$ & Demand deposit, foreign exchange deposit, time deposit \\
Fixed assets $\left(x_{2}\right)$ & Lands, equipments, structures, etc. \\
Capital $\left(x_{3}\right)$ & Total value utilising by banks to raise deposits \\
Output factor & Definition \\
Non-interest income $\left(y_{1}\right)$ & Interest income subtracted from operating revenue \\
& The aggregate value of bonds and stocks that a bank hold \\
\hline
\end{tabular}

Table 2

Descriptive Statistics of the Inputs/Outputs of Nine Malaysian Banks (2004-2013)

S.D refers to standard devition measure

Source: annual report of the banks. Note: AFIN: AFFIN HOLDINGS, MYPB: Alliance Financial Group, AMMB: AMMB Holdings, BIMB: BIMB Holdings, COMBS: CIMB Group Holdings, HOLB: Hong Leong Bank, HONG: Hong Leong Financial Group, MALY: Malayan Banking, RHBC: RHB Capital.

\section{Results and Discussions}

The two-stage SE-SBM model needs to be applied to calculate the efficiency scores of the banks. The first stage uses SBM model (2) to discriminate among efficient and inefficient banks during the period of evaluation, the efficiency score of each inefficient bank is less than one. In contrast to this, the efficiency score of each efficient bank is equal to one. To discriminate and rank the efficient banks resulted from model (2); super efficiency model (4) is run as the second stage. Hence, the efficiency scores of the superefficient and inefficient banks are presented in Table 3.
Table 3 presents that the efficiency status of the banks fluctuated over the examined period, the high number of the efficient banks can be observed in the years 2006 and 2008 by six for each of which (i.e., the efficient banks are $66 \%$ ). For years 2005, 2009, 2010, and 2011, $33 \%$ of the banks are efficient, while the year 2012 has the lowest number of the efficient banks where only two are efficient out of the nine banks. 
Efficiency Scores of Two-Stage SE-SBM Model

\begin{tabular}{|c|c|c|c|c|c|c|c|c|c|c|c|}
\hline Banks/Years & 2004 & 2005 & 2006 & 2007 & 2008 & 2009 & 2010 & 2011 & 2012 & 2013 & 10-year Average \\
\hline AFIN & 1.0005 & 0.9630 & 0.9446 & 0.9764 & 0.9716 & 0.9752 & 0.9656 & 0.9624 & 0.9502 & 0.9708 & 0.9680 \\
\hline MYPB & 0.9600 & 0.9427 & 0.9389 & 0.9808 & 0.9734 & 0.9688 & 0.9711 & 1.0003 & 0.9723 & 0.9667 & 0.9675 \\
\hline AMMB & 1.0132 & 1.0128 & 1.0021 & 1.0072 & 1.0069 & 0.9735 & 0.9767 & 0.9766 & 0.9712 & 1.0105 & 0.9951 \\
\hline BIMB & 1.0072 & 1.0049 & 1.1301 & 1.0053 & 1.0029 & 1.0132 & 1.0153 & 1.0135 & 1.0229 & 1.0291 & 1.0244 \\
\hline COMBS & 1.0037 & 0.9736 & 1.0027 & 1.0047 & 1.0061 & 1.0025 & 1.0011 & 0.9900 & 0.9856 & 1.0005 & 0.9971 \\
\hline HOLB & 0.9608 & 0.9422 & 0.9745 & 0.9807 & 0.9880 & 0.9788 & 0.9724 & 0.9380 & 0.9603 & 0.9530 & 0.9649 \\
\hline HONG & 1.0041 & 1.0186 & 1.0008 & 1.0012 & 1.0020 & 0.9870 & 0.9873 & 0.9836 & 0.9661 & 0.9609 & 0.9912 \\
\hline MALY & 0.9951 & 0.9806 & 1.0031 & 0.9849 & 1.0040 & 1.0001 & 1.0009 & 1.0103 & 1.0147 & 1.0002 & 0.9994 \\
\hline RHBC & 0.9932 & 0.9801 & 1.0040 & 1.0018 & 1.0024 & 0.9838 & 0.9729 & 0.9729 & 0.9584 & 0.9732 & 0.9843 \\
\hline $\begin{array}{c}\text { Yearly } \\
\text { Average }\end{array}$ & 0.9930 & 0.9798 & 1.0000 & 0.9936 & 0.9952 & 0.9869 & 0.9848 & 0.9830 & 0.9779 & 0.9849 & \\
\hline
\end{tabular}

We can see that BIMB has achieved the super-efficient status over the examined period; thus, its rank is the first at most of the years, i.e., six years as shown in Table 4. The banks COMBS and MALY have achieved the superefficient status for seven years of the examined period, i.e., $77 \%$ of the evaluation period, while the number of times that the banks AMMB, HONG, and RHBC have realized the super efficiency is six, five, and three, respectively. Only one bank which is HOLB out of the total nine banks has not realized the super-efficient status; therefore, its rank is low among other banks, this provides an indicator to low performance of the mentioned bank. Moreover, the ranking of the nine banks are fluctuated among increase and decrease except BIMB was relatively stable at first rank as presented in Table 4.

Ranks of the Banks Based on Efficiency Scores of Two-Stage SE-SBM Model

\begin{tabular}{|c|c|c|c|c|c|c|c|c|c|c|}
\hline Banks/Years & 2004 & 2005 & 2006 & 2007 & 2008 & 2009 & 2010 & 2011 & 2012 & 2013 \\
\hline AFIN & 5 & 7 & 8 & 9 & 9 & 7 & 9 & 8 & 9 & 6 \\
\hline MYPB & 9 & 8 & 9 & 7 & 8 & 9 & 8 & 3 & 4 & 7 \\
\hline AMMB & 1 & 2 & 5 & 1 & 1 & 8 & 5 & 6 & 5 & 2 \\
\hline BIMB & 2 & 3 & 1 & 2 & 4 & 1 & 1 & 1 & 1 & 1 \\
\hline COMBS & 4 & 6 & 4 & 3 & 2 & 2 & 2 & 4 & 3 & 3 \\
\hline HOLB & 8 & 9 & 7 & 8 & 7 & 6 & 7 & 9 & 7 & 9 \\
\hline HONG & 3 & 1 & 6 & 5 & 6 & 4 & 4 & 5 & 6 & 8 \\
\hline MALY & 6 & 4 & 3 & 6 & 3 & 3 & 3 & 2 & 2 & 4 \\
\hline RHBC & 7 & 5 & 2 & 4 & 5 & 5 & 6 & 7 & 8 & 5 \\
\hline
\end{tabular}

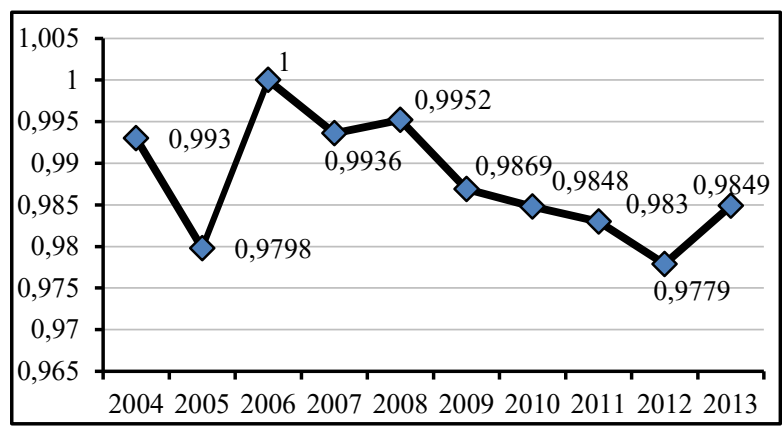

Figure 1. Yearly Average of Efficiency Scores of Nine Commercial Banks

In addition, the average of efficiency scores obtained from the two-stage model is restricted between 0.9779 and 1. About $90 \%$ of the banks are inefficient as yearly average, this indicates that the super efficiency scores of the efficient banks are small, i.e., the non-radial distance between an excluded efficient bank to the efficient frontier is small (Lo \& Lu, 2009). Regarding to the averages of the overall efficiency, Figure 1 depicts that the average efficiency of Malaysian banking sector has decreased in the year 2005 and increased at 2006, and then significantly decreased after 2006 to 2012 because of the financial crisis on the commercial Malaysian banks. However, the banks started to improve their performance in year 2013 since their trend has started to increase. In general, the figure shows that the average efficiency score decreased over the examined period, especially after 2006. To observe the average efficiency of each bank over the evaluation period, Figure 2 illustrates the ten-year average of efficiency scores of each of the bank. Clearly, BIMB is ranked first with score of 1.0244, followed by COMBS and AMMB at second and third positions, respectively, while HOLB is at the lowest position for the years 2004-2013.

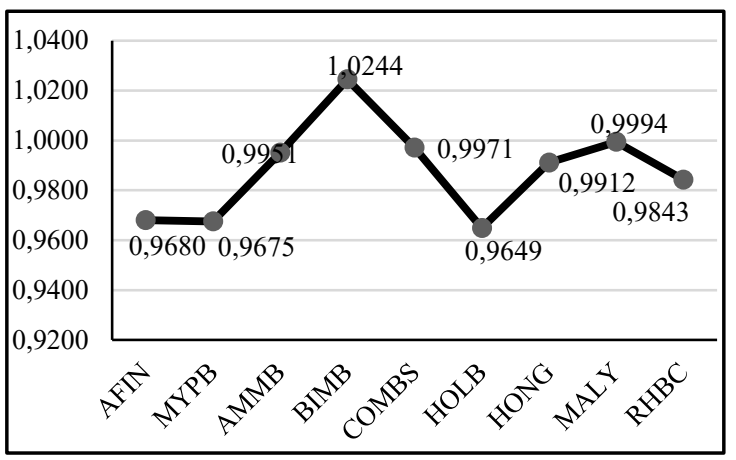

Figure 2. Ten-Year (2004-2013) Average of Efficiency Scores of Each Bank

\section{Comparison between the Super Efficiency Radial and SE-SBM Model}

The efficiency scores of Malaysian banks over the evaluation period are calculated using the super efficiency radial model proposed by Andersen and Petersen (1993) as presented in Table 5. The efficiency scores reported in Table 5 are compared to that obtained from the SE-SBM model which presented in Table 3. 
Maznah Mat Kasim, Razamin Ramli, Md. Azizul Baten, Jastini Mohd Jamil, Mushtaq Taleb. Efficiency of Banks in ...

Efficiency Scores of the Super Radial Model

\begin{tabular}{|c|c|c|c|c|c|c|c|c|c|c|c|}
\hline Banks/Years & 2004 & 2005 & 2006 & 2007 & 2008 & 2009 & 2010 & 2011 & 2012 & 2013 & 10-year Average \\
\hline AFIN & 1.0017 & 0.9825 & 0.9789 & 0.9934 & 0.9859 & 0.9921 & 0.9715 & 0.9678 & 0.9566 & 0.9908 & 0.9821 \\
\hline MYPB & 0.9683 & 0.9472 & 0.9679 & 0.9901 & 0.9812 & 0.9832 & 0.9743 & 1.0004 & 0.9776 & 0.9814 & 0.9772 \\
\hline AMMB & 1.0301 & 1.0300 & 1.0065 & 1.0154 & 1.0179 & 0.9925 & 0.9876 & 0.9806 & 0.9742 & 1.0212 & 1.0056 \\
\hline BIMB & 1.0193 & 1.0149 & 1.3905 & 1.0161 & 1.0088 & 1.0331 & 1.0338 & 1.0289 & 1.0406 & 1.0570 & 1.0643 \\
\hline COMBS & 1.0080 & 0.9871 & 1.0079 & 1.0124 & 1.0113 & 1.0041 & 1.0029 & 0.9951 & 0.9918 & 1.0017 & 1.0022 \\
\hline HOLB & 0.9704 & 0.9549 & 0.9958 & 0.9949 & 0.9983 & 0.9835 & 0.9754 & 0.9457 & 0.9712 & 0.9706 & 0.9761 \\
\hline HONG & 1.0124 & 1.0204 & 1.0022 & 1.0025 & 1.0047 & 0.9907 & 0.9917 & 0.9908 & 0.9770 & 0.9839 & 0.9976 \\
\hline MALY & 0.9966 & 0.9915 & 1.0063 & 0.9883 & 1.0087 & 1.0005 & 1.0022 & 1.0211 & 1.0303 & 1.0003 & 1.0046 \\
\hline RHBC & 0.9963 & 0.9915 & 1.0115 & 1.0038 & 1.0050 & 0.9912 & 0.9793 & 0.9782 & 0.9690 & 0.9908 & 0.9917 \\
\hline $\begin{array}{c}\text { Yearly } \\
\text { Average for } \\
\text { all banks }\end{array}$ & 1.0003 & 0.9911 & 1.0408 & 1.0018 & 1.0024 & 0.9967 & 0.9909 & 0.9898 & 0.9875 & 0.9997 & \\
\hline
\end{tabular}

The efficiency scores of the SE-SBM model are less than or equal to that of the super radial model (see Tone, 2001, p. 505; 2002, p.39). Therefore, Table 3 has shown that all efficiency scores of the SE-SBM model are less than or equal to that of the super radial model presented in Table 5 . Consequently, the yearly averages of efficiency scores of the SE-SBM model for all banks are also less than of that resulted by the super radial model as shown in the mentioned tables and Figure 3. This ensures that the two super efficiency models were applied in an effective manner. The efficiency status of the efficient and inefficient banks during the period of evaluation are same for the two models since the efficiency scores obtained from the super radial model are greater than or equal to that resulted by the SE-SBM model. Due to the efficiency measurement of the non-radial SBM model determines by the values of reference set, the model can eliminate biases in its efficiency measures (Tone, 2001). Hence, the efficiency scores of the efficient and inefficient banks obtained from the SE-SBM model are more stable of that resulted by the super radial model.

The stability of the two models' results can be presented through their averages of efficiency scores as display in Figures 3 and 4 . Figure 3 shows the average of efficiency scores resulted from the two models for the nine banks during the period of evaluation, while Figure 4 shows the average of efficiency scores of the two models also but for each bank over the examined period. Through the two figures, we can observe that the average of efficiency scores resulted from the SE-SBM model is more stable than of the super radial model over evaluation period, this provides another significant indicator to the robust results of the SE-SBM model.

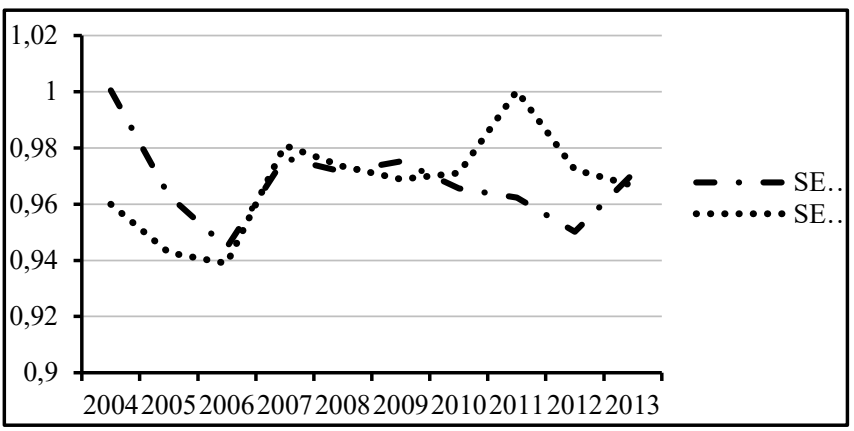

Figure 3. Yearly Average Efficiency Scores of Super Radial and SE-SBM Models

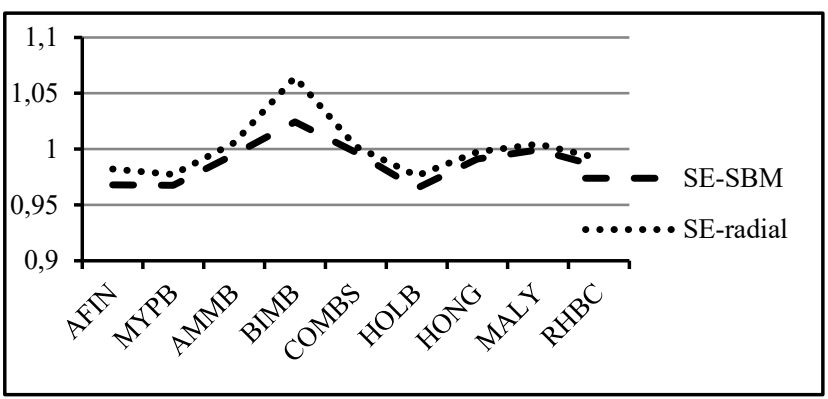

Figure 4. Ten-Year Efficiency Average Score for Each Bank

\section{Conclusions}

The non-radial SBM model measures the efficiency of DMUs in an effective manner since it deals with slacks of input and output simultaneously at different rates, which is the limitation of the radial model. However, when the radial model was used to measure the efficiency of Malaysian banks, the radial model cannot properly rank efficient banks because these banks have the same efficiency score. The performance of banks having same efficiency scores and same ranks, cannot be differentiated or discriminated. Therefore, in this paper, the SE-SBM model, proposed by Tone (2002) is utilized in ranking efficient nine Malaysian banks. The salient features of the model are its ability to discriminate the efficient and inefficient DMUs and ranking them, in addition it has the ability to identify slacks of input excess and output shortfall for each inefficient unit to improve its performance. In Malaysia; however, there have not been studies employed the SE-SBM model in evaluating Malaysian banks sector. Thus, with the aim to evaluate the efficiency of Malaysian banking sector, and to rank the efficient banks as well, this paper adopts the two stages of SE-SBM model. For the first time, the efficiency of commercial banks in Malaysia has been evaluated using the SE-SBM model of Tone (2002), and the efficient banks were able to be ranked for each year under study, which significantly contributes to the literature of banks efficiency.

The empirical results illustrate that the efficiency of the nine main Malaysian commercial banks has greatly decreased between 2006 and 2012. However, the high number of the efficient banks, with different rankings can be observed in years 2006 and 2008. The BIMB has achieved the super-efficient status for all examined years; therefore, its rank is the first in the most years of the examined period. In contrast to this, HOLB bank has 
achieved low rank among the other banks since its status is inefficient over the examined period. Moreover, the average efficiency scores of the most banks are inefficient; this provides an indicator that the efficiency status of the banks is greatly fluctuated over the period of evaluation. The data set of Malaysian banks were re-examined by calculating the efficiency scores using the super radial model. For this, a comparison between the results obtained from the SE-SBM and that of the super radial models is performed. The results of the SE-SBM models are more stable of that obtained from the super radial model. For the decision makers, the inefficient banks could improve their performance by calculating their real projections of inputs and outputs.

This paper has three limitations. First, performance evaluation of Malaysian commercial banks was only compared among the Malaysian banks. More accurate efficiency measures can be obtained, if other developed Asian countries such as Japan and Singapore dataset are included. Second, due to cost constraint faced by the research team to get more recent data, the study did not able to cover more recent data, for example up to 2016. However, it is believed that the ten-year study period is not that short period of time and the findings are still relevant for reference regarding the future direction of Malaysian banking industry. In upcoming research, more recent data with different categories of banks should be considered, so that more high impact findings are plausible. Third, the dataset used in this paper consists of bad output, which is non-interest income, this factor is more likely to be dealt as undesirable output. Therefore, a new SE-SBM model with undesirable output can be proposed. All these venues can be executed as future directions for this paper.

\section{Acknowledgement}

The authors wish to acknowledge the financial support provided by the High Impact Group Research Grant (PBIT) with S/O Code 12870, Universiti Utara Malaysia, Sintok, Kedah, Malaysia, for conducting this research.

\section{References}

Ab Rahim, R. (2015). Ranking of malaysian commercial banks: super-efficiency data envelopment analysis (DEA) approach. Asian Academy of Management Journal of Accounting \& Finance, 11(1).

Andersen, P., \& Petersen, N. C. (1993). A procedure for ranking efficient units in data envelopment analysis. Management Science, 39(10), 1261-1264. https://doi.org/10.1287/mnsc.39.10.1261

Asmild, M., \& Matthews, K. (2012). Multi-directional efficiency analysis of efficiency patterns in Chinese banks $1997-$ 2008. European Journal of Operational Research, 219(2), 434-441. https://doi.org/10.1016/j.ejor.2012.01.001

Ataullah, A., Cockerill, T., \& Le, H. (2004). Financial liberalization and bank efficiency: a comparative analysis of India and Pakistan. Applied Economics, 36(17), 1915-1924. https://doi.org/10.1080/000368404200068638

Ataullah, A., \& Le, H. (2006). Economic reforms and bank efficiency in developing countries: the case of the Indian banking industry. Applied Financial Economics, 16(9), 653-663. https://doi.org/10.1080/09603100500407440

Avkiran, N. K. (2011). Association of DEA super-efficiency estimates with financial ratios: Investigating the case for Chinese banks. Omega, 39(3), 323-334. https://doi.org/10.1016/j.omega.2010.08.001

Baten, M. A., Kasim, M. M., \& Rahman, M. (2015). Cost and profit efficiency of online banks: Do national commercial banks perform better than private banks? Journal of Internet Banking and Commerce, 20(3), 1-19. https://doi.org/10.4172/1204-5357.1000138

Casu, B., \& Molyneux, P. (2003). A comparative study of efficiency in European banking. Applied Economics, 35(17), 1865-1876. https://doi.org/10.1080/0003684032000158109

Charnes, A., \& Cooper, W. W. (1962). Programming with linear fractional functionals. Naval Research Logistics Quarterly, 9(3-4), 181-186. https://doi.org/10.1002/nav.3800090303

Charnes, A., Cooper, W. W., \& Rhodes, E. (1978). Measuring the efficiency of decision making units. European Journal of Operational Research, 2(6), 429-444. https://doi.org/10.1016/0377-2217(78)90138-8

Charnes, A., Cooper, W., Golany, B., Seiford, L., \& Stutz, J. (1985). Foundations of data envelopment analysis for ParetoKoopmans efficient empirical production functions. Journal of Econometrics, 30(1-2), 91-107. https://doi.org/10.1016/0304-4076(85)90133-2

Chiu, Y. H., Chen, Y. C., \& Bai, X. J. (2011). Efficiency and risk in Taiwan banking: SBM super-DEA estimation. Applied Economics, 43(5), 587-602. https://doi.org/10.1080/00036840802599750

Chiu, Y. H., Jan, C., Shen, D. B., \& Wang, P. C. (2008). Efficiency and capital adequacy in Taiwan banking: BCC and super-DEA estimation. The Service Industries Journal, 28(4), 479-496. https://doi.org/10.1080/02642060801917604

Cook, W. D., \& Seiford, L. M. (2009). Data envelopment analysis (DEA) - Thirty years on. European Journal of Operational Research, 192(1), 1-17. https://doi.org/10.1016/j.ejor.2008.01.032 
Maznah Mat Kasim, Razamin Ramli, Md. Azizul Baten, Jastini Mohd Jamil, Mushtaq Taleb. Efficiency of Banks in ...

Cooper, W. W., Park, K. S., \& Pastor, J. T. (1999). RAM: a range adjusted measure of inefficiency for use with additive models, and relations to other models and measures in DEA. Journal of Productivity Analysis, 11(1), 5-42. https://doi.org/10.1023/A:1007701304281

Deng, C. G., Liu, T., \& Wu, J. (2007). Efficiency analysis of China's commercial banks based on DEA: Negative output investigation. China-USA Business Review, 6(2), 50-56.

Du, J., Liang, L., \& Zhu, J. (2010). A slacks-based measure of super-efficiency in data envelopment analysis: a comment. European Journal of Operational Research, 204(3), 694-697. https://doi.org/10.1016/j.ejor.2009.12.007

Duzakın, E., \& Duzakın, H. (2007). Measuring the performance of manufacturing firms with super slacks based model of data envelopment analysis: An application of 500 major industrial enterprises in Turkey. European Journal of Operational Research, 182(3), 1412-1432. https://doi.org/10.1016/j.ejor.2006.09.036

Favero, C. A., \& Papi, L. (1995). Technical efficiency and scale efficiency in the Italian banking sector: a non-parametric approach. Applied Economics, 27(4), 385-395. https://doi.org/10.1080/00036849500000123

Hussain, M. T., Ramli, R., \& Khalid, R. (2016). A hybrid integer data envelopment analysis based on an alternative approach of super slack based measure for measuring super efficiency and inefficiency of decision making units. Far East Journal of Mathematical Sciences, 100(1), 147-170. https://doi.org/10.17654/MS100010147

Khodabakhshi, M., Asgharian, M., \& Gregoriou, G. N. (2010). An input-oriented super-efficiency measure in stochastic data envelopment analysis: Evaluating chief executive officers of US public banks and thrifts. Expert Systems with Applications, 37(3), 2092-2097. https://doi.org/10.1016/j.eswa.2009.06.091

Levine, R. (1998). The legal environment, banks, and long-run economic growth. Journal of Money, Credit and Banking, 596-613. https://doi.org/10.2307/2601259

Li, Z. (2006). The assessment analysis of efficiency of commercial banks based on DEA model. International Management Review, 2(3), 60-66.

Lo, S. F., \& Lu, W. M. (2009). An integrated performance evaluation of financial holding companies in Taiwan. European Journal of Operational Research, 198(1), 341-350. https://doi.org/10.1016/j.ejor.2008.09.006

McAllister, P. H., \& McManus, D. (1993). Resolving the scale efficiency puzzle in banking. Journal of Banking \& Finance, 17(2-3), 389-405. https://doi.org/10.1016/0378-4266(93)90039-G

Morita, H., Hirokawa, K., \& Zhu, J. (2005). A slack-based measure of efficiency in context-dependent data envelopment analysis. Omega, 33(4), 357-362. https://doi.org/10.1016/j.omega.2004.06.001

Ouenniche, J., \& Carrales, S. (2018). Assessing efficiency profiles of UK commercial banks: A DEA analysis with regression-based feedback. Annals of Operations Research. 266, 1-2, pp.551-587. https://doi.org/10.1007/s10479018-2797-z

Staub, R. B., Souza, Z. G. S., \& Tabak, B. M. (2010). Evolution of bank efficiency in Brazil: A DEA approach. European Journal of Operational Research 202, pp. 204-213. https://doi.org/10.1016/j.ejor.2009.04.025

Sturm, J. E., \& William, B. (2004). Foreign bank entry, deregulation and bank efficiency: Lessons from the Australian experience. Journal of Banking \& Finance 28, pp. 1775-1799. https://doi.org/10.1016/j.jbankfin.2003.06.005

Sufian, F., \& Haron, R. (2009). On the efficiency of the Malaysian banking sector: a risk-return perspective. International Journal of Commerce and Management, 19(3), 222-232. https://doi.org/10.1108/10569210910987994

Sufian, F., \& Kamarudin, F. (2014). Efficiency and Returns to Scale in the Bangladesh Banking Sector: Empirical Evidence from the Slack-Based DEA Method. Inzinerine Ekonomika-Engineering Economics, 25(5), $549-557$. https://doi.org/10.5755/j01.ee.25.5.5035

Taleb, M., Ramli, R., \& Khalid, R. (2018). Developing a two-stage approach of super efficiency slack-based measure in the presence of non-discretionary factors and mixed integer-valued data envelopment analysis. Expert Systems with Applications, 103, 14-24. https://doi.org/10.1016/j.eswa.2018.02.037

Titko, J., Stankeviciene, J., \& Lace, J. (2014). Measuring bank efficiency: DEA application. Technological and Economic Development of Economy, 20 (4), pp. 739-757. https://doi.org/10.3846/20294913.2014.984255

Tone, K. (2001). A slacks-based measure of efficiency in data envelopment analysis, 130 (3), $498-509$. https://doi.org/10.1016/S0377-2217(99)00407-5

Tone, K. (2002). Continuous Optimization A slacks-based measure of super-efficiency in data envelopment analysis, 143, 32-41. https://doi.org/10.1016/S0377-2217(01)00324-1

Wang, K., Huang, W., Wu, J. \& Liu, Y. (2014). Efficiency measures of the Chinese commercial banking system using an additive two-stage DEA. Omega 44, 5-20. https://doi.org/10.1016/j.omega.2013.09.005 
Wang Q., Hang Y., Sun, L., \& Zhao, Z. (2016). Two-stage innovation efficiency of new energy enterprises in China: A non-radial DEA approach. Technological Forecasting and Social Change. 112, pp. 254-261.). https://doi.org/10.101 6/j.techfore.2016.04.019

Yin, Z., Yu, Y., \& Huang, J. (2018) Evaluation and evolution of bank efficiency considering heterogeneity technology: An empirical study from China. PLos One, 13(10), pp. 1-19. https://doi.org/10.1371/journal.pone.0204559

Zha, Y., Liang, N., Wu, M., \& Bian, Y. (2016). Efficiency evaluation of banks in China: A dynamic two-stage slack-based measure approach. Omega, 60, pp 60-72. https://doi.org/10.1016/j.omega.2014.12.008

Zhao, H., \& Kang, S. (2015). Banking Performance Evaluation in China Based on Non-radial Super-efficiency Data Envelopment Analysis. Procedia Economics and Finance 23, pp. 19-202. https://doi.org/10.1016/S2212-5671(15) 00387-1

The article has been reviewed. Received in October 2017; accepted in October 2019. 